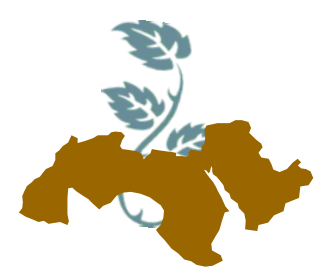

\title{
EXTRACTION AND EVALUATION OF BIOACTIVE COMPOUNDS FROM SOME FRUIT AND VEGETABLE PEELS
}

\author{
Eman, E.I. Yousef, Nagwa, M.H. Rasmy, I.R.S. Rizk and Hanan, M.A. Al-Sayed \\ Food Sci. Dept., Fac. of Agric., Ain Shams Univ., Cairo, Egypt \\ E-mail of corresponding author: Eman_es 2007@yahoo.com
}

Keywords: Fruit and vegetable peels, Antioxidant activity, Phenolics, Flavoniods, Extraction

\section{ABSTRACT}

Different research reports have revealed that food industry by-products can be considered as good sources of potentially valuable bioactive compounds. This study was performed to evaluate the antioxidant capacity of the peel extracts of pomegranate (PoP), mango (MaP), prickly-pear $(\mathrm{PrP})$, Cantaloupe $(\mathrm{CaP})$ and pea $(\mathrm{PeP})$ using different solvent polarity (methanol, ethanol, ethylacetate and water) to particular attention to their content of total phenolics and flavoniods. Among all tested extracts, ethanolic extracts of $\mathrm{PoP}, \mathrm{MaP}$ and PrP and aqueous extract of CaPand PeP were shown to exhibited a significant $(p \leq 0.05)$ highest extraction yield, total phenolic and flavonoid contents and antioxidant capacity (measured by DPPH,ABTS and FRAP methods). The antioxidant capacity of different peel extracts was showed the following descending order, $\mathrm{MaP}>\mathrm{PoP}>\mathrm{PrP}>\mathrm{CaP} \approx \mathrm{PeP}$. Also there was a strong positive correlation between the DPPH, ABTS, FRAP values and total phenolic as well as, flavoniod contents of different peels extracts. Seventeen phenolic compounds were identified and quantified by HPLC-UV analysis in different peel extracts. Galic acid was identified as the major compound in MaP and PoP extracts, while it was rutin in the case PrP,CaPand PeP extracts. From the results obtained, fruit and vegetable peels can be considered as good sources of valuable bioactive compounds.

\section{INTRODUCTION}

Considerable amount of solid wastes in the form of peels and seeds are generated by the fruit and vegetable industries, these wastes if not disposed correctly are seen to cause serious environmental problems and economic losses. Recently ,it was reported that $39 \%$ of food waste is produced by the food manufacturing industries in developed countries. There are several reports highlighting the integral exploitation of bioactive compounds from these wastes and their potential application as antioxidant, antimicrobial, flavoring, colorant, and texturized agents. Peels are the major by- products obtained during the processing of various fruits and these were shown to be a good source of polyphenols, carotenoids and other bioactive compounds which posses various beneficial effects on human health (Mirabella et al 2014 and Roy and Lingampeta 2014).

One of the principal causes of food quality deterioration is lipid peroxidation .Lipid peroxidation results in formation of reactive oxygen species and free radicals ; which are purportedly associated with carcinogenesis, mutagenesis, inflammation ,DNA changes, aging and cardiovascular diseases. To prevent the lipid peroxidation in fats and oils, synthetic antioxidants (BHA and $\mathrm{BHT}$ ) have been used as food additives for over 50 years (Shahidi et al 1997).

Nowadays great interest is awarded to natural antioxidants due to problems related to safety and toxicity of synthetic antioxidant. Many natural antioxidants have already been isolated from different plants such as oil seeds, cereals, vegetables, leaves, roats, herbs and spices (Chaouch et al 2015)

Pomegranate peels( Punica granatum L.) are considered non - edible parts or by products $(50 \%$ of fruit weight) obtained during juice processing .It is characterized by the significant presence of polyphenols such as ellagitannins, ellagic acid,gallic acid and flavoniods associated with biological 
properties such as antioxidant and antimicrobial agents (Akhtar, 2015; Faria \& Calahau, 2010; Glazer et al 2012; Marchi et al 2015; Negi et al 2003)

Major by- product of mango (Mangifera indica $L$.) processing are peels and seeds, amounted of 35 and $60 \%$ of the total fruit weight respectively. The peels of mango has a significant potential benefit due to its powerful antioxidant properties and high content of phenolic compounds. The major phenolic compounds of ripe and unripe mango peels are gallic acid, syringic acid, gentisylprotocatechic,mangiferin,ellogic acid and quercetin (Tunchaiyaphum et al 2013).

Peels of Prickly pear represent a large proporation of the whole fruit (from 40 to $50 \%$ ) and constitute a source of bioactive compounds, notably phenolics, flavonoids and betalains ( Arrizan et al 2006 and Kuti, 2004). Chougui et al (2015) found that hydro - ethanolic extract of prickly pear peels (Opuntica-ficius- indica) was rich in total phenolics (1512.58 mg GAE/100gDM). HPLC analyses allowed the identification of sixteen compounds belonging to hydroxyl benzoic acid, hydroxycinnamic acids and flavoniods.

Hadrich et al (2014) indicated that the peel of pea (pisum sativum) represented a source of active compounds essentially phenols and flavonoids with antioxidant activity. The ability of the peel pea extracts, and BHT as a positive control ,to reduce $\mathrm{Fe}^{3+}$ to $\mathrm{Fe}^{2+}$ was determined. The reducing capacity of peel of pea extracts (ethylacetate, methanol and water ) differed significantly in their activity.

Extraction is an important step in the isolation and later in the identification and quantification of phenolic compounds (Cacace and Mazza, 2003) Since the phenolic compounds of different plants differ structurally, it is very difficult to develop a standardized extraction method that would simultaneously extract all inherent phenolic compounds (Naczk and Shahidi, 2006).

Optimization of extraction conditions to yield the maximum level of food grade antioxidant phenolics involves, the type of solvent,or solvent ratio,the particle size of the plant material,the solvent- solid ratio, extraction temperature and time (Akhtar et al 2015).

Methanol, ethanol, or propanol and their mixtures in water as well as the acetone,ethyl acetate and dimethyl from a mide are so far the most commonly used solvents in the extraction of phenolic compounds from the plant materials (Escribano-Bailon \& Santos-Buelga 2003 and Naczk \& Shahidi, 2006).
The objective of this study was carried out to determine the content of total phenolics, total flavonids and antioxidant capacity extracted from peels of pomogrenate, mango, prickly pear cactus, by pea, cantaloupe and using five different solvents.

In addition,the phenolic acids profile of these peel extracts were identified using HPLC technique to get insight into the compounds responsible for the antioxidant activity of these by - product.

\section{MATERIALS AND METHODS}

\section{Chemicals}

Gallic acid, 2,2-diphenyl -1-picryl-hydrazyl (DPPH) , 2,2 azinobis (3- ethyl - benzothiozoline 6sulfonic, acid) (ABTS) , 2,4,6-tripyridyl -s, triazine (PTZ), Folin-Ciocalteu reagent solvents for HPLC analysis and the individual phenolic standars were purchased from Sigma-Aldrich, Inc.(Louis, USA). All other chemicals, solvents and reagents used were of analytical grade and the experiment was carried out in triplicate.

\section{Plant materials and sample preparation}

Pomegranate (Punica granatum L.), mango (Mangifera indica L.), prickly pear cactus (Opuntia ficus- indica), pea (Pisum sativum), cantaloupe (Cucumis melo) were obtained from local market, in Cairo, Egypt during 2014/2015

The peels of different materials were manually removed, cut into pieces and dried in an air oven at $55 \pm 2{ }^{\circ} \mathrm{C}$ for $8 \mathrm{~h}$. The dried sample was grounded using coffe grinder, passed through a 40-mesh sieve and stored in polyethylene bags at $-18{ }^{\circ} \mathrm{C}$ until analysis.

\section{Preparation of plant peel extracts}

Bioactive compounds of plant peel samples were extracted using different solvents including (methanol, ethanol, ethyl acetate \& their combinations (in 1:1:1) and water). Twenty gram of each peel powder sample were stirred with $100 \mathrm{ml}$ of each solvent for $4 \mathrm{hr}$ at room temperature. The extracts were filtrated through whatman No 42 filter paper to remove peel particles and dried at $40^{\circ} \mathrm{C}$ under vaccum. The yield was calculated as grams of extract obtained after drying. Each of the dried peel extract sample was stored in closed vial at $4^{\circ} \mathrm{C}$ (Roy et al 2014). 


\section{Determination of total phenolic content}

Total phenolics of different peel extracts were determined according to the method of Jayaprakasha and Lingam Peta (2001) using FolinCiocalteu reagent. Portiors $400 \mu \mathrm{l}$ of diluted extracts were taken in test tubes; $1.0 \mathrm{ml}$ of FolinCiocalteu reagent (diluted 10 -fold with distilled water) and $0.8 \mathrm{ml}$ of $7.5 \%$ sodium carbonate were added. The tubes were mixed and allowed to stand for $30 \mathrm{~min}$ in dark at room temperature before the absorbance was measured at 760nm using labomed. Inc. spectrophotomer (Spectro UV - VIS Double Beam / UVD-3500) against blank, which contained $400 \mu \mathrm{l}$ of ethanol in place of sample. The amount of phenolics present in the sample was determined from a standard curve prepared with gallic acid in $95 \%$ ethanol. The total phenolic content was expressed as gallic acid equivalents in $\mathrm{mg} / \mathrm{g}$ dried extract.

\section{Determination of total flavonoid content}

Total flavoniods were estimated by using spectrophotometeric assay as described by $\mathbf{K i m}$ et al (2003) with simple modifications. Each extract $(50 \mu \mathrm{l})$ was mixed with water $(500 \mu \mathrm{l})$ and $200 \mu \mathrm{l}$ sodium nitrate $(150 \mathrm{~g} / \mathrm{l})$. After $6 \mathrm{~min}$ of agitation, $100 \mu \mathrm{l}$ of aluminum chloride $(100 \mathrm{~g} / \mathrm{l})$ was added. Then the mixture was indicated for $5 \mathrm{~min}$., before $1 \mathrm{ml}$ of $40 \mathrm{~g} / \mathrm{l} \mathrm{NaoH}$ solution was added. The mixture was diluted to final volume of $2.5 \mathrm{ml}$ with distilled water and mixed thoroughly. The absorbance was measured at $510 \mathrm{~nm}$. Catachine was used to make the calibration curve. Total flavoniod content was expressed as mg catachine equivalent (CE) / $\mathrm{g}$ dried extract.

\section{Determination of antioxidant activity of differ-} ent peel extracts

\section{DPPH radical scavenging activity}

The capacity of peels extracts to scavenging DPPH was measured based on the method of Hwang and Do Thi (2014). This method depends on the reduction of purple DPPH radicals to yellow colored DPPH and the remaining DPPH radicals that show maximum absorption at $517 \mathrm{~nm}$ was measured .Briefly $100 \mu \mathrm{l}$ of peel extract was allowed to react $3.95 \mathrm{ml}$ of DPPH solution $(0.2 \mathrm{mM}$ DPPH in methanol). The decrease in absorbance was determined at $517 \mathrm{~nm}$ using Labomed. Incspectrophotometer, against blank of pure metha- nol after 60 min of incubation in a dark condition. Trolox was used to make the calibration curve. The antioxidant activity was expressed as $\mathrm{mg}$ trolox equivalent / g extract.

\section{ABTS cation radical-scavenging assay}

The stock solutions of ABTS reagent was prepared according to Hwang and Do Thi (2014) by reacting equal quantities of a $7 \mathrm{mM}$ aqueous solution of ABTS with $2.45 \mathrm{mM}$ potassium persulfate for $16 \mathrm{~h}$ at room temperature $(25 \circ \mathrm{C})$ in the dark . The working solution was then prepared by diluting $1 \mathrm{ml}$ ABTS solution with $60 \mathrm{ml}$ of ethanol : water $(50: 50, v / v)$ to obtain an absorbance of $1.0 \pm 0.02$ units at $734 \mathrm{~nm}$. Extracts $((50 \mu \mathrm{l})$ were allowed to react with $4.95 \mathrm{ml}$ of the ABTS solution for $1 \mathrm{~h}$ in a dark condition. Then the absorbance was taken at $734 \mathrm{~nm}$ using the spectrophotometer. Results was expressed as mg Trolox equivalents (TE)/g sample.

Ferric- reducing antioxidant power assay
(FRAP)

The FRAP assay was carried out according to the method of Hwang and Do Thi (2014). FRAP reagent was prepared with $25 \mathrm{ml}$ acetate buffer (300 mM, pH 3.6),2.5 ml $10 \mathrm{~m} \mathrm{M} \mathrm{TPTZ} \mathrm{solution} \mathrm{in}$ $40 \mathrm{mM} \mathrm{Hcl}$, and $2.5 \mathrm{ml}$ of $20 \mathrm{mM}$ ferric chloride hexahydrate. FRAP reagent was prepared freshly .The mixture was warmed at $37^{\circ} \mathrm{C}$ before use . $50 \mu \mathrm{l}$ of peel extract samples were allowed to react with $3.95 \mathrm{ml}$ FRAP solution for $30 \mathrm{~min}$ in a dark condition. Readings of the color product (ferrous tripyridyltraizine complex) were then taken at 593 $\mathrm{nm}$. The standard curve was prepared using trolox. Results was expressed as mg Trolox equivalents (TE)/gsample. Additional dilution was needed if the FRAP value measured was over the linear range of standard.

\section{Analysis of phenolic compounds by HPLC}

Phenolic compounds were analysed by HPLC using agilent Technologies 1100 series liquid chromatograph equipped with an auto sampler and diode-array detector. The analytical column was a Eclipse XDB-C18 (150x $4.6 \mu \mathrm{m}, 5 \mu \mathrm{m})$ with a C18 guard column (Agilent, USA). The mobile phase consisted of acetonitrile (solvent $A$ ) and $2 \%$ acetic acid in water $(\mathrm{v} / \mathrm{v})$ (solvent $\mathrm{B})$. The flow rate was kept at $0.8 \mathrm{ml} / \mathrm{min}$ for total run time of $70 \mathrm{~min}$ and 
the gradient program was as follows $: 100 \% B$ to $85 \% \mathrm{~B}$ in $30 \mathrm{~min}, 85 \%$ Bto $50 \% \mathrm{~B}$ in $20 \mathrm{~min}, 50 \% \mathrm{~B}$ to $0 \% \mathrm{~B}$ in $5 \mathrm{~min}$. Extract were prepared as mentioned previously and were evaporated at $40 . \mathrm{C}$ using a rotary evaporator. The injection volume was $50 \mu \mathrm{l}$ and peaks were monitored simultaneously at 280 and $320 \mathrm{~nm}$ for the benzoic acid and cinnamic acid derivatives, respectively. All samples were filtered through a. 45 Acrodisc syringe filter (Gelman Laboratory, MI) before injection. Peaks were identified and compared with those standars. (Yahia and Mondragon, 2011).

\section{Statistical analysis}

All samples were analyzed in triplicates and the results were expressed as means \pm standard deviation (SD). Analysis was assessed using the Statical Analysis System Software System for windows (SAS, 2008). One way analysis of variance (ANOVA) was performed to evaluate the significant differences between sample means, with significant level being considered at $p<0.05$. Means comparisons were assessed by Duncan 's test.

\section{RESULTS AND DISCUSSION}

Extraction of bioactive compounds from pomegranate, mango, prickly pear, cantaloupe and pea peels using different solvents was comparative with antioxidant activity of the extracts as follows

\section{Extraction yield}

Table (1) represents the yield values obtained from fruit and vegetable peels extracted with solvents of a different polarity. Depending on the extraction solvent, yield $\%$ significantly $(p<0.05)$ differed among peel extracts. The yield \% of different solvents varied from 34.86 to $50.37 \%$, 24.2840.57\%, 24.22-33.86\%,12.42-20.21\% and 11.01$25.05 \%$ from the extracts of (PoP), (MaP), (PrP), $(\mathrm{CaP})$ and $(\mathrm{PeP})$ respectively. Among all tested extracts, it appears that ethanolic extract showed the highest yield from PoP, MaP and PrP, while water extract exhibited the most yield from $\mathrm{CaP}$ and PeP.

This result is in a contrast with those obtained by Ismail et al (2010), Li et al (2006) and Marchi et al (2015) for cantaloupe skin, and Shiban et al (2012) for pomegranate peels. Whereas, it differed from Hardich et al (2014) who proved that methanol is the most suitable solvent for extraction of bioactive compounds from peel of pea. Moreover, ethanol and water are safer and therefore more suitable for the food industry than the other organic solvents (Huh et al 2004).

Table 1. Yield (\%w/w) of different solvent extracts from fruit and vegetable peels

\begin{tabular}{|c|c|c|c|c|c|}
\hline $\begin{array}{c}\text { Peels } \\
\text { Extracts }\end{array}$ & $\begin{array}{l}\text { Pomegranate } \\
\text { (PoP) }\end{array}$ & $\begin{array}{c}\text { Mango } \\
\text { (MaP) }\end{array}$ & $\begin{array}{l}\text { Prickly pear } \\
\text { (PrP) }\end{array}$ & $\begin{array}{c}\text { Cantaloupe } \\
\text { (CaP) }\end{array}$ & $\begin{array}{c}\text { Pea } \\
\text { (PeP) }\end{array}$ \\
\hline Methanol(M) & $47.95^{\mathrm{AB}} \pm 2.0$ & $34.52^{\mathrm{B}} \pm 1.5$ & $30.74^{A B} \pm 2.0$ & $13.24^{\mathrm{B}} \pm 0.45$ & $15.22^{\mathrm{B}} \pm 0.0$ \\
\hline Ethanol(E) & $50.37^{A} \pm 1.45$ & $40.57^{A} \pm 0.0$ & $33.86^{A} \pm 0.0$ & $17.51^{\mathrm{A}} \pm 1.12$ & $18.54^{\mathrm{B}} \pm 0.24$ \\
\hline $\begin{array}{l}\text { Ethyl acetate } \\
\text { (EA) }\end{array}$ & $45.61^{B} \pm 2.5$ & $28.16^{C} \pm 1.84$ & $29.31^{\mathrm{B}} \pm 1.48$ & $12.42^{B} \pm 2.0$ & $11.01^{\mathrm{C}} \pm 1.11$ \\
\hline $\begin{array}{l}\text { M:E:EA } \\
(\text { ratio1:1:1) }\end{array}$ & $47.62^{\mathrm{AB}} \pm 0.0$ & $34.28^{\mathrm{B}} \pm 0.04$ & $31.94^{A} \pm 1.11$ & $16.25^{\mathrm{AB}} \pm 1.5$ & $16.27^{\mathrm{B}} \pm 1.56$ \\
\hline Water (W) & $34.86^{\mathrm{C}} \pm 1.55$ & $24.28^{C} \pm 0.85$ & $24.22^{B} \pm 1.18$ & $20.21^{A} \pm 0.12$ & $25.05^{\mathrm{A}} \pm 0.45$ \\
\hline
\end{tabular}

Values (mean \pm S.D.) with different letters within the same column are significantly different $(p \leq 0.05)$ 


\section{Total phenolic and flavonoid contents}

Several studies have revealed that the phenolic content in the plants are associated with their antioxidant activities, probably due to their redox properties, which allow them to act as reducing agent, hydrogen donors and singlet oxygen quenchers (Chang et al 2001). Flavonoids are the most common and widely distributed group of phenolic compounds, which usually are very effective antioxidants (Yanish lieva-Maslarova, 2001).

It can be noticed from Tables (2) and (3) that total phenolic (TP) and flavonoid (TF) contents of different peel extracts were significantly $(p \leq 0.05)$ differed depending on the peel source and solvent
type.Based on the solvent system, ethanolics extracts of PoP, MaPand PrP and water extract of $\mathrm{CaP}$ and PeP exhibited the highest levels of TP and TF contents. However, among the different tested peel samples ethanolic extracts of PoP and MaP recorded the highest TP ( 93.77 and 181.65 $\mathrm{mg}$ gallic acid $/ \mathrm{g}$ ) and TF (17.57 and $14.71 \mathrm{mg}$ catachine/g) respectively. These results were accordance with the results of extraction yield. Similar results were obtained by Negi et al (2003) and Shiban et al (2012) for pomegranate peels, Tunchaiyaphum et al (2013) for mango peels, Abdel-Hameed et al (2014) for prickly pear peels, Ismail et al (2010) for cantaloupe skin and Hardish et al (2014) for peel of pea.

Table 2. Total phenolic (TP) content (mg gallic acid/g) of different extracts from some fruit and vegetable peels

\begin{tabular}{|c|c|c|c|c|c|}
\hline Extracts $\quad$ Peels & $\begin{array}{l}\text { Pomegranate } \\
\text { (PoP) }\end{array}$ & $\begin{array}{l}\text { Mango } \\
(\mathrm{MaP})\end{array}$ & $\begin{array}{l}\text { Prickly pear } \\
\text { (PrP) }\end{array}$ & $\begin{array}{c}\text { Cantaloupe } \\
\text { (CaP) }\end{array}$ & $\begin{array}{l}\text { Pea } \\
\text { (PeP) }\end{array}$ \\
\hline Methanol(M) & $\begin{array}{l}81.35^{\mathrm{F}} \\
\pm 0.03\end{array}$ & $\begin{array}{c}134.99^{\mathrm{B}} \\
\pm 3.09\end{array}$ & $\begin{array}{c}30.15^{\text {HIJ }} \\
\pm 0.98\end{array}$ & $\begin{array}{c}30.83^{\text {HIJ }} \\
\pm 0.10\end{array}$ & $\begin{array}{c}24.33^{\mathrm{KIJ}} \\
\pm 0.31\end{array}$ \\
\hline Ethanol(E) & $\begin{array}{l}93.77^{\mathrm{D}} \\
\pm 2.06\end{array}$ & $\begin{array}{c}181.65^{\mathrm{A}} \\
\pm 2.6\end{array}$ & $\begin{array}{c}61.62^{G} \\
\pm 1.6\end{array}$ & $\begin{array}{c}15.00^{\mathrm{K}} \\
\pm 0.15\end{array}$ & $\begin{array}{c}27.02^{\mathrm{HIJ}} \\
\pm 0.1\end{array}$ \\
\hline Ethyl acetate(EA) & $\begin{array}{c}87.13^{\mathrm{E}} \\
\pm 5.6\end{array}$ & $\begin{array}{r}123.75^{c} \\
\pm 1.03\end{array}$ & $\begin{array}{c}24.69^{\mathrm{IKJ}} \\
\pm 0.36\end{array}$ & $\begin{array}{c}32.12^{\mathrm{HI}} \\
\pm 0.00\end{array}$ & $\begin{array}{c}20.38^{\mathrm{KJ}} \\
\pm 0.41\end{array}$ \\
\hline M:E:EA & $76.71^{\mathrm{F}}$ & $124.70^{C}$ & $33.23^{\mathrm{HI}}$ & $25.52^{\text {HIJK }}$ & $26.19^{\mathrm{HIJ}}$ \\
\hline (ratio1:1:1) & \pm 1.5 & \pm 2.06 & \pm 0.15 & \pm 0.36 & \pm 0.20 \\
\hline Water (W) & $\begin{array}{l}52.47^{\mathrm{H}} \\
\pm 4.11\end{array}$ & $\begin{array}{c}35.51^{\mathrm{H}} \pm \\
0.05\end{array}$ & $\begin{array}{c}32.63^{\mathrm{HI}} \\
\pm 1.03\end{array}$ & $\begin{array}{c}33.64^{\mathrm{HI}} \\
\pm 1.03\end{array}$ & $\begin{array}{c}48.45^{\mathrm{G}} \\
\pm 0.46\end{array}$ \\
\hline
\end{tabular}

Values (mean \pm S.D.) with different letters within the same column and row are significantly different $(p \leq 0.05)$

Table 3. Total flavoniod (TP) content (mg catachine/g) of different extracts from some fruit and vegetable peels

\begin{tabular}{|c|c|c|c|c|c|}
\hline $\begin{array}{ll}\text { Extracts } & \text { Peels } \\
\end{array}$ & $\begin{array}{c}\text { Pomegranate } \\
\text { (PoP) }\end{array}$ & $\begin{array}{c}\text { Mango } \\
(\mathrm{MaP})\end{array}$ & $\begin{array}{c}\text { Prickly pear } \\
\text { (PrP) }\end{array}$ & $\begin{array}{c}\text { Cantaloupe } \\
\text { (CaP) }\end{array}$ & $\begin{array}{l}\text { Pea } \\
\text { (PeP) }\end{array}$ \\
\hline Methanol(M) & $17.24^{\mathrm{A}}$ & $10.39^{\mathrm{C}}$ & $0.82^{G}$ & $1.70^{\mathrm{G}}$ & $6.78^{D}$ \\
\hline & \pm 0.03 & \pm .0 .16 & \pm 0.12 & \pm 0.03 & \pm 0.18 \\
\hline Ethanol(E) & $17.57^{\mathrm{A}}$ & $14.71^{\mathrm{B}}$ & $0.99^{G}$ & $2.27^{\mathrm{G}}$ & $6.58^{D}$ \\
\hline & \pm 2.06 & \pm 0.00 & \pm .03 & \pm 0.06 & \pm 0.13 \\
\hline Ethyl ace- & $13.75^{\mathrm{B}}$ & $13.56^{\mathrm{B}}$ & $0.96^{G}$ & $1.66^{G}$ & $6.94^{\mathrm{D}}$ \\
\hline tate $(\mathrm{EA})$ & \pm 5.6 & \pm 1.43 & \pm 0.03 & \pm 0.00 & \pm 0.13 \\
\hline M:E:EA & $13.41^{\mathrm{B}}$ & $13.74^{\mathrm{B}}$ & $1.25^{\mathrm{ED}}$ & $2.38^{\mathrm{GF}}$ & $6.17^{\mathrm{G}}$ \\
\hline (ratio1:1:1) & \pm 1.5 & \pm 0.23 & \pm 0.04 & \pm 1.02 & \pm 0.07 \\
\hline Water (W) & $2.07^{G}$ & $4.32^{\mathrm{EF}}$ & $0.57^{G}$ & $9.82^{C}$ & $7.08^{D}$ \\
\hline & \pm 4.11 & \pm 0.48 & \pm 0.04 & \pm 0.00 & \pm 0.16 \\
\hline
\end{tabular}

Values (mean \pm S.D.) with different letters within the same column and row are significantly different $(p \leq 0.05)$ 


\section{Antioxidant activity}

The antioxidant capacity of different fruit and vegetable peels extracts measured by the use of ABTS, FRAP and DPPH assays are presented in Table (4). Overall comparison of different solvents showed ethanol, methanol, ethylacetate and their mixture extracts of PoP and MaP exhibited significant $(p<0.05)$ stronger activity( DPPH and ABTS values), while water extract of the same peels showed lower activity. Similar results were obtained with FRAP assay for PoP and MaP extracts. Prickly pear (PrP) extracted with ethanol and mixture of methanol, ethanol and ethylacetate had significantly $(p<0.05)$ higher antioxidant activity than those extracted with water. On the contrary, water extract of $\mathrm{CaP}$ and PeP significantly $(p<0.05)$ exhibited higher antioxidant activity compared to other tested solvents (Table 4).

Among all tested extracts ethanolic extracts exhibited the strongest antioxidant capacity measured by ABTS,FRAP and DPPH assays, being 243.05,357.9 and $257.38 \mathrm{mg}$ torloex $/ \mathrm{g}$ PoP, $315.5,319.5$ and $343.02 \mathrm{mg}$ torolex $/ \mathrm{g} \mathrm{MaP}$, and 199.8, 222.08 and $209.70 \mathrm{mg}$ torolex /g PrP respectively. On the other hand, aqueous extracts of $\mathrm{CaP}$ and $\mathrm{PeP}$ recorded higher antioxidant activity measured by ABTS,FRAP and DPPH being 164.9,211.4 and 182.5,215.3 $\mathrm{mg}$ torolex /g PeP and 195.2 and $200.4 \mathrm{mg}$ torelex /g CaP respectively. In conclusion, the antioxidant capacity of different peels extracts was showed the following despending order; mango> pomegranate>prickly pear (ethanolic extract) > cantaloupe $\approx$ pea (water extract).

Previously, Li et al (2006) found extraction of pomegranate peel with a mixture of ethanol and acetone had a higher antioxidant capacity than pulp extract. Also, Negi et al (2003), found that acetone, ethyl acetate and methanol peel extracts of pomegranate exhibited a higher antioxidant capacity, but the water extract was the lowest. Abdel-Hameed et al (2014) showed that the juices of peels and pulps of red cactus exhibited a higher reducing power activity (149.49 and $123.23 \mathrm{mg}$ ascorbic acid equivalent $/ 100 \mathrm{ml}$ juice respectively. Our results are in contrast with the reports of Lee et al (2007) and Hadrich et al (2014) showed that water is the most suitable solvent for extraction of phenolic compounds from the peel of pea (pisum sativum). Jahural et al (2015) reported that mango peel extracts were proven to be a good source of polyphenols, anthocyanins and carotenoids and thus, they may be used in nutraceutical and functional foods as a source of antioxidant agents.

Table 4. Antioxidant activity of different solvent extracts obtained from some fruit and vegetable peels

\begin{tabular}{|c|c|c|c|}
\hline \multirow{3}{*}{ Solvents } & \multicolumn{3}{|c|}{ Antioxidant assay } \\
\hline & $\begin{array}{c}\text { ABTS } \\
\text { mg Trolox/g }\end{array}$ & $\begin{array}{c}\text { FRAP } \\
\text { mg Trolox/g }\end{array}$ & $\begin{array}{c}\text { DPPH } \\
\text { mg Trolox/g }\end{array}$ \\
\hline & \multicolumn{3}{|c|}{ Pomegrenate peel } \\
\hline Methanol(M) & $229.9^{A} \pm 29.57$ & $314.5^{\mathrm{B}} \pm 3.4$ & $237.70^{A} \pm 14.1$ \\
\hline Ethanol(E) & $243.05^{\mathrm{A}} \pm 9.20$ & $357.9^{\mathrm{A}} \pm 13.4$ & $257.38^{A} \pm 6.08$ \\
\hline $\begin{array}{c}\text { Ethyl ace- } \\
\text { tate(EA) }\end{array}$ & $231.64^{\mathrm{A}} \pm 21.9$ & $344.5^{\mathrm{A}} \pm 4.1$ & $245.30^{A} \pm 11.12$ \\
\hline $\begin{array}{c}\text { M:E:EA (ra- } \\
\text { tio1:1:1) }\end{array}$ & $239.8^{A} \pm 15.8$ & $335.7^{\mathrm{AB}} \pm 1.06$ & $228.3^{\mathrm{A}} \pm 18.1$ \\
\hline \multirow[t]{2}{*}{ Water (W) } & $162.9^{B} \pm 19.34$ & $202.6^{\mathrm{C}} \pm 4.11$ & $128.9^{B} \pm 1.2$ \\
\hline & \multicolumn{3}{|c|}{ Mango peel } \\
\hline Methanol(M) & $282.2^{\mathrm{B}} \pm 2.0$ & $389.7^{\mathrm{A}} \pm 2.5$ & $324.8^{B} \pm 1.2$ \\
\hline Ethanol(E) & $315.5^{\mathrm{A}} \pm 17.4$ & $391.5^{\mathrm{A}} \pm 4.3$ & $343.02^{\mathrm{A}} \pm 2.4$ \\
\hline $\begin{array}{c}\text { Ethyl ace- } \\
\text { tate(EA) }\end{array}$ & $306.8^{\mathrm{AB}} \pm 4.7$ & $383.2^{A B} \pm 12.4$ & $325.8^{\mathrm{B}} \pm 1.8$ \\
\hline $\begin{array}{c}\text { M:E:EA (ra- } \\
\text { tio1:1:1) }\end{array}$ & $302.3^{A B} \pm 5.3$ & $367.02^{\mathrm{B}} \pm 3.5$ & $321.7^{\mathrm{B}} \pm 3.0$ \\
\hline \multirow[t]{2}{*}{ Water (W) } & $129.19^{\mathrm{C}} \pm 6.1$ & $156.9^{\mathrm{C}} \pm 3.22$ & $226.6^{\mathrm{C}} \pm 0.6$ \\
\hline & \multicolumn{3}{|c|}{ Prickly - pear peel } \\
\hline Methanol(M) & $146.8^{\mathrm{C}} \pm 5.5$ & $136.22^{c} \pm 13.4$ & $208.5^{A} \pm 7.2$ \\
\hline Ethanol(E) & $199.8^{A} \pm 1.5$ & $222.08^{A} \pm 17.5$ & $209.7^{\mathrm{A}} \pm 2.4$ \\
\hline $\begin{array}{c}\text { Ethyl ace- } \\
\text { tate(EA) }\end{array}$ & $146.6^{\mathrm{c}} \pm 8.1$ & $129.15^{\mathrm{D}} \pm 9.06$ & $178.7^{\mathrm{B}} \pm 0.6$ \\
\hline $\begin{array}{c}\text { M:E:EA (ra- } \\
\text { tio1:1:1) }\end{array}$ & $\begin{array}{l}165.34^{B} \\
\pm 10 . .02\end{array}$ & $178.15^{\mathrm{B}} \pm 7.9$ & $101.09^{\mathrm{D}} \pm 9.02$ \\
\hline \multirow[t]{2}{*}{ Water (W) } & $\begin{array}{c}116.34^{\mathrm{D}} \\
\pm 12.5 \\
\end{array}$ & $139.9^{c} \pm 5.6$ & $138.9^{\mathrm{C}} \pm 0.00$ \\
\hline & \multicolumn{3}{|c|}{ Cantaloupe peel } \\
\hline Methanol(M) & $147.7^{1 \mathrm{~B}} \pm 13.2$ & $151.8^{\mathrm{B}} \pm 11.7$ & $148.4^{\mathrm{c}} \pm 2.4$ \\
\hline Ethanol(E) & $135.6^{\mathrm{B}} \pm 9.5$ & $148.4^{B} \pm 12.6$ & $175.18^{\mathrm{AB}} \pm 7.8$ \\
\hline $\begin{array}{c}\text { Ethyl ace- } \\
\text { tate(EA) }\end{array}$ & $\begin{array}{l}117.5^{\mathrm{C}} \\
\pm 11.04\end{array}$ & $127.4^{B} \pm 6.2$ & $156.8^{B} \pm 14.4$ \\
\hline $\begin{array}{c}M: E: E A(r a- \\
\text { tio1:1:1) }\end{array}$ & $140.9^{B} \pm 2.5$ & $194.8^{A} \pm 13.8$ & $172.9^{\mathrm{AB}} \pm 1.8$ \\
\hline \multirow[t]{2}{*}{ Water (W) } & $182.5^{A} \pm 15.2$ & $215.3^{\mathrm{A}} \pm 11.6$ & $200.4^{\mathrm{A}} \pm 1.8$ \\
\hline & \multicolumn{3}{|c|}{ Pea peel } \\
\hline Methanol(M) & $124.8^{\mathrm{AB}} \pm 6.2$ & $158.6^{\mathrm{B}} \pm 1.9$ & $155.9^{C} \pm 1.2$ \\
\hline Ethanol(E) & $83.7^{\mathrm{B}} \pm 11.8$ & $100.3^{C} \pm 10.02$ & $109.8^{\mathrm{D}} \pm 0.00$ \\
\hline $\begin{array}{c}\text { Ethyl ace- } \\
\text { tate(EA) }\end{array}$ & $110.8^{\mathrm{AB}} \pm 14.9$ & $131.7^{\mathrm{BC}} \pm 11.9$ & $165.4^{\mathrm{B}} \pm 3.6$ \\
\hline $\begin{array}{c}\text { M:E:EA (ra- } \\
\text { tio1:1:1) }\end{array}$ & $88.11^{B} \pm 1.4$ & $165.3^{B} \pm 9.7$ & $110.9^{\mathrm{D}} \pm 0.00$ \\
\hline Water (W) & $164.9^{A} \pm 12.02$ & $211.4^{\mathrm{A}} \pm 8.4$ & $195.2^{A} \pm 0.6$ \\
\hline
\end{tabular}

Values (mean \pm S.D.) with different letters within the same column for each peel waste extract are significantly different $(p \leq 0.05)$ 


\section{Correlation between antioxidant capacity and total phenolic and flavonoid contents}

The correlation between total phenolic, flavonoid contents and antioxidant capacity of different peel extracts were calculated and the results are given in Table (5).

Table 5. Correlation coefficient between antioxidant activity total phenolic and flavoniods contents of different peel extracts

\begin{tabular}{|c|c|c|c|c|c|}
\hline Trait & $\begin{array}{c}\text { Flavo- } \\
\text { noid }\end{array}$ & phenol & ABTS & FRAP & DPPH \\
\hline Flavonoid & 1.00 & 0.73 & 0.71 & 0.82 & 0.61 \\
phenol & 0.73 & 1.00 & 0.85 & 0.89 & 0.82 \\
ABTS & 0.71 & 0.85 & 1.00 & 0.80 & 0.78 \\
FRAP & 0.82 & 0.89 & 0.80 & 1.00 & 0.75 \\
DPPH & 0.61 & 0.82 & 0.78 & 0.75 & 1.00 \\
\hline
\end{tabular}

A strong linear relationships could be observed between the total phenolic content and antioxidant capacity of different peels extracts $\left(R^{2}=0.82,0.89\right.$ and 0.85 for DPPH, FRAP and ABTS values, respectively). Also, there was a positive linear correlation between the total flavonoids and antioxidant capacity of the peel extracts $\left(R^{2}=0.61,0.82\right.$ and 0.71 for DPPH, FRAP and ABTS values, respectively). The correlations between the results of antioxidant activity and the total phenolic and flavonoid contents indicated that polyphenol compounds largely contributed to the antioxidant capacities of the selected fruit and vegetable peels. The positive linear relationships between the total phenolic contents and antioxidant capacity were in accordance with the result of other researches (Chen et al 2014; Fu et al 2011 and Song et al 2010).

Comparisons were also evaluated between the results obtained by the DPPH, FRAP and ABTS assays. A high correlation was observed between FRAP and ABTS values $\left(R^{2}=0.80\right)$, ABTS and DPPH values $\left(R^{2}=0.78\right)$ and FRAP and DPPH values $\left(R^{2}=0.746\right)$, which suggested that the com pounds capable of reducing oxidants also could scavenge free radicals in these peels extracts. Similar results were obtained by Chen et al (2014). Also, there was a high correlation between total phenolic and flavonoids contents of different peels extracts $\left(R^{2}=0.73\right)$.

\section{Identification and quantification of phenolic} compounds of different peel extracts

The ethanolic extracts of PoP, MaP and PrP and aqueous extracts of $\mathrm{CaP}$ and $\mathrm{PeP}$ were subjected to HPLC analysis so as to investigate the types of phenolic compounds responsible for the antioxidant activity of these peel extracts.

In this study, seventeen phenolic compounds were identified and quantified in the peel samples extracts by comparing the HPLC chromatograms of them with the HPLC chromatograms of standard compounds based on the retention at the same conditions (Table 6).

As seen from Table (6), rutin, coumarin and ferulic acid were identified in all tested peel extracts, whereas, gentisic, chlorgenic acid, syrngic acid, vanillic acid and chyrsin were identified in only one sample of different peel extracts.

Gallic acid was identified as the major compounds in MaP (95.04\%) and PoP (65.73\%) extracts, while, it was rutin in the case of $\mathrm{PrP}, \mathrm{CaP}$ and PeP extracts. Also, it is clearly noticed that $\mathrm{MaP}$ extract exhibited the highest amount of gallic acid $(11739.35 \mu \mathrm{g} / \mathrm{g})$ followed by PoP extract $(7818.80 \mu \mathrm{g} / \mathrm{g})$ and $\mathrm{CaP}$ extract $(123.33 \mu \mathrm{g} / \mathrm{g})$ On the other hand, CaP extract contained the most amount of rutin $(2007.17 \mu \mathrm{g} / \mathrm{g})$ followed by PrP and PeP extracts (1263.04 and $309.23 \mu \mathrm{g} / \mathrm{g}$ respectively).

HPLC analysis showed that the content of phenolic compounds of the peel wastes extracts have the following order, mango>pomegranate> cantaloupesprickly-pear and pea. This finding is supported by the fact that the ethanolic extract of MaP and PoP which has shown the best antioxidant activity in the present study has more content of phenolic compounds (mainly gallic acid) as seen in Table (6). 
Table 6. Quantity of phenolic compounds $(\mu \mathrm{g} / \mathrm{g})$ identified by HPLC analysis of different peel extracts

\begin{tabular}{|c|c|c|c|c|c|c|}
\hline \multirow{2}{*}{ Compounds } & Rt & \multicolumn{5}{|c|}{ Peel extracts of } \\
\cline { 3 - 7 }$(\mathbf{m i n})$ & pomegranate & Mango & Prickly -pear & cantaloupe & Pea \\
\hline Gallic acid & 5.5 & 7818.801 & 11739.354 & 0.000 & 123.331 & 0.00 \\
protochatchuic acid & 9.5 & 220.687 & 238.541 & 48.367 & 0.000 & 35.196 \\
gentisic acid & 16.5 & 0.000 & 0.000 & 27.666 & 0.000 & 0.000 \\
catachine & 17.9 & 682.248 & 119.104 & 0.000 & 0.000 & 141.218 \\
chlorgenic acid & 20.0 & 0.000 & 26.805 & 0.000 & 0.000 & 0.000 \\
caffeic acid & 20.6 & 11.916 & 0.000 & 0.000 & 731.056 & 4.272 \\
syrngic acid & 22.1 & 142.697 & 0.000 & 0.000 & 0.000 & 0.000 \\
vanillic acid & 23.7 & 0.000 & 0.000 & 0.000 & 137.080 & 0.000 \\
Rutin & 35.8 & 205.284 & 58.240 & 1263.043 & 2007.169 & 309.230 \\
coumarin & 36.7 & 293.773 & 24.696 & 49.316 & 75.664 & 50.917 \\
ferulic acid & 31.5 & 792.468 & 50.941 & 11.724 & 2.435 & 1.484 \\
sinapic acid & 33.1 & 501.825 & 85.588 & 13.360 & 5.154 & 0.000 \\
rosmarinic acid & 40.0 & 651.772 & 0.000 & 55.305 & 19.178 & 6.160 \\
cinnamic acid & 42.5 & 0.000 & 9.096 & 13.736 & 18.935 & 0.865 \\
Qurecetin & 43.2 & 274.705 & 0.000 & 23.440 & 0.000 & 5.404 \\
Kaempferol & 46.1 & 42.464 & 0.000 & 0.000 & 0.000 & 3.356 \\
chyrsin & 51.5 & 245.451 & 0.000 & 0.000 & 0.000 & 0.000 \\
\hline Total & & 11884.08 & 12352.36 & 1505.96 & 3120.01 & 558.10 \\
\hline
\end{tabular}

\section{REFERENCES}

Abdel-Hameed, E.S., Nagaty, M.A., Salman, M.S. and Bazaid, S.A. 2014. Phytochemicals, nutritionals and antioxidant properties of two prickly pear cactus cultivars(opuntia ficus indica Mill) growing in Taif, KSA. Food Chem.160, 31-38.

Akhtar, S., Ismail, T., Fraternale, D. and Sestili, P. 2015. Pomegrenate peel and peel extracts: Chemistry and food features: Review. Food Chem.174, 417-425.

Arrizan, J., Calderon, C. and Sandoval, G. 2006. Effect of different fermentation conditions on the kienitic parameters and production of volatile compounds during the elaboration of a prickly pear distilled beverage. J. Industrial Microb. and Biotechnol.33, 921-928.

Cacace, J.E. and Mazza, G. 2003. Mass transfer process during extraction of phenolic compounds from milled berries. Food and Eng.,59,379-389.

Chang, S.T., Wu, J.H. Wang, S.Y., Kang, P.L., Yang, N.S. and Shyur, L.F. 2001. Antioxidant activity of extracts from Acacia confuse bark and heartwood. J. Agric. and Food Chem., 49(7), 3420-3424.

Chaouch, M.A., Hafsa, J., Rihouey, C., Cerf, D.L. and Majdoub, H. 2015. Depolymerization of polysaccharides from opuntia ficus indica:
Antioxidant and antiglycated activities. Inter. J. Biological Macromolecules.79, 779-786.

Chen, G., Chen, S., Zhao, Y. and Luo, C. 2014. Total phenolic contents of 33 fruits and their antioxidant capacities before and after in vitro digestion. Industrial Crops and Products. 57,150-157.

Chougui, N., Djerroud, N., Naraoui, F., Hadjal, S., Aliane, K., Zeroual, B. and Larbat, R. 2015. Physicochemical properties and storage stability of margarine containing Opuntia ficusindica peel extract as antioxidant. Food Chem.173, 382-390.

Escribano-Bailon, M.T. and Santos-Buelga, C. 2003. Polyphenols extraction from foods. In "Methods in polyphenol Analysis", SantosBuelga, C. and Williamson, G. (eds.), pp.1-16, Royal Society of Chem. Cambridge, UK

Faria, A. and Calhau, C. 2010. Pomegrenate in human health: An overview. Bioactive foods in promoting health: fruits and vegetables. Watson, R.R. and Preedy, V.R. (eds). pp. 551563.Academic press, Amsterdam, Netherlands.

Fu, L., Txu, B., Xu, X. R., Gan, R.Y., Zhang, Y., Qxia, E. and La, H.B. 2011. Antioxidant capacities and total phenolic contents of 62 fruits. Food Chem.129, 345-350.

Glazer, L., Masaphy, S., Marciano, P., Bar-llan, I., Holland, D., Kerem, Z. and Amir, R. 2012. Partial identification of antifungal compounds 
from punica granatum peel extracts. J. Agric. and Food Chem. 60, 4841-4848.

Hadrich, F., ElArbi, M., Boukhris, M., Sayadi, S. and Cherif, S. 2014. Valorization of the peel of pea: Pisum sativum by evaluation of its antioxidant and antimicrobial activites. J. Oleo Sci.63(11), 1177-1183.

Huh, Y.S., Hong, T.H. and Hong, W.H. 2004. Effective extraction of oligomeric proanthocyanidin (OPC) from wild grape seeds. Biotech. Bioprocess Eng. 9, 471-475.

Hwang, E.S. and Do Thi, N. 2014. Effects of extraction and processing method on antioxidant activities of lavar (porphyra tenera). Preventive Nutri. and Food Sci., 19, 40-48.

Ismail, H.I., Chan, K.W., Mariod, A.A. and Ismail, M. 2010. Phenolic content and antioxidant activity of cantaloupe (Cucmis melo) methanolic extracts. Food Chem.119, 643647.

Jahurul, M.H.A., Zaidul, I.S.M., Ghafoor, K., Nyam, K., Norulaini, N.A.N., Sahena, F. and Omar, A.K.M. 2015. Mango (Mangifera indica,l.) by-products and their valuable components:A review. Food Chem.183,173-180.

Jayaprakasha, G.K., Singh, R.P. and Sakariah, K.K. 2001. Antioxidant activity of grape seed (Vitis vinifera) extracts on peroxidation models in vitro. Food Chem.73, 285-290.

Kim, D.O., Jeong, S.W. and Lee, C.Y. 2003. Antioxidant capacity of phenolic phytochemicals from various cultivars of plums. Food Chem., 81, 321-326.

Kuti, J.O. 2004. Antioxidant compounds from four Opuntia cactus pear fruit varieties. Food Chem., 85, 527-533.

Lee, Y.L., Huang, G.W., Liang, Z.C. and Mau, G.L. 2007. Antioxidant properties of three extracts from Pleurotus citrinopileatus. LWTFood Sci. Technol., 40, 823-833.

Li, Y., Guo, C., Yang, J., Wei, J., Xu, J. and Cheng, S. 2006. Evaluation of antioxidant properties of pomegranate pulp extract. Food Chem., 96, 54-260.

Marchi, L.B., Monteiro, A.R.G., Mikcha, J.M.G., Santos, A.R., Chinellato, M.M., Marques, D.R., Dacome, A.S. and Costa, S.C. 2015. Evaluation of antioxidant and antimicrobial capacity of pomegranate peel extract (punica Granatum I.) under different drying tempera- tures. Chemical Engineering Transactions, 44, 12-20.

Mirabella, N., Castellani, V. and Sala, S. 2014. Current options for the valorization of food manufacturing waste. A review. J. Cleaner Production, 65, 28-41.

Naczk, M. and Shahidi, F. 2006. Phenolics in cereals, fruits and vegetables occurrence, extraction and analysis.J. Pharm. Biomed. Anal., 41, 1523-1542.

Negi, S.P., Jayaprakasha, K.G. and Jena, S.B. 2003. Antioxidant and antimutagenic activities of pomegranate peel extracts. Food Chem., 80, 393-397.

Roy, S. and Lingampeta, P. 2014 .Solid wastes of fruits peels as source of low cost broad spectrum natural antimicrobial compoundes furfral and benzenetriol. Inter. J. Research in Eng. and Technol. 3(7), 273-279.

SAS System 2008. Statistical Analysis System. Version 9.2. Cary, USA: SAS Institute Inc.

Shahidi, F., Amarovicz, R., Abou-Gharbia, H.A. and Shehata, A.A.Y. 1997. Endogenous antioxidants and stability of sesame oil as affected by processing and storage. J. Amer. Oil Chem. Soci., 74, 143-147.

Shiban, M.S., Al- Otaibi, M.M. and AQI-Zoreky, N.S. 2012. Antioxidant activity of pomegranate (Punica granatum I.) fruit peels. Food and Nutr. Sci., 3, 991-996.

Song, F.L., Gan, R.Y., Zang, Y., Xiao, Q., Kuang, I. and Li, H.B. 2010. Total phenolic contents and antioxidant capacities of selected Chinese medicinal plants. Int. J. Mol. Sci., 11, 23622372.

Tunchaiyaphum, S., Eshtiaghi, M.N. and Yoswathana, N. 2013. Extraction of bioactive compounds from mango peels using green technology. Inter. J. Chem. Eng. and Applications. 4(4), 194-198.

Yahia, E.M. and Mondragon, C. 2011. Nutritional components and antioxidant capacity of ten cultivars and linis of cactus pear fruit (Opuntia spp.). Food Res. Inter. 44, 2311-2318.

Yanishlieva- Maslarova, N.V. 2001. Inhibiting oxidation, in" Antioxidants in food: practical application", Pokorny, J., Yanishlieva, N. and Gordon, M.H. (eds). pp. 22-70, Cambridge: Wood Head Publ. Limited. 